\title{
Optimization Design of Water System in Coal Chemical Industry Based on Water Pinch Analysis
}

\author{
Ru-feng Xiao ${ }^{a 1^{*}}$ and Feng Cai ${ }^{\text {b1 }}$ \\ ${ }^{1}$ Chongqing Academy of Environmental Science, Chongqing 401147 China \\ a448477905@qq.com
}

Keywords: Water Pinch Point, Water Networks, Optimal Design, Water-Saving

\begin{abstract}
In order to cut down fresh water consumption and reduce wastewater emission in industrial production, water pinch technology principle was introduced to optimize the design of water supply network of the coal chemical industry. The results show that under the premise of ensuring adequate water consumption of each unit, the influent COD concentration of each unit do not exceed the maximum water quality limits, and the drainage of each unit had achieved maximum COD load to achieve maximum utilization of water resources. And compared to the fresh water consumption of $960 \times 104 \mathrm{t} / \mathrm{a}$ before optimization, the water consumption was $749.94 \times 104 \mathrm{t} / \mathrm{a}$ with an annual saving rate of $21.88 \%$, so the water saving effect was significant.
\end{abstract}

\section{Introduction}

With a rapid development of economy, water shortage and water pollution have become a global issue. In China, water shortage is highly serious and the quantity per capita is only a quarter of the world average. However, the effective utilization rate of water resources is universally low not only in agricultural activities but in industrial productions as well. The industrial enterprises have occupied a large proportion of water consumption. Correspondingly, the water pollution caused by industrial wastewater discharge has become a troublesome problem. Therefore, it is of significance to strengthen the promotion of high-efficiency water saving work and decrease the waste water exhaust quantity. As a matter of fact, a large number of researches have been conducted for such purposes in the worldwide. As one of the most significant research achievements in such field, water pinch technology theory was first proposed by Wang et al. in $1994^{[1]}$. Through the continuous improvement, it hasbeen getting more mature in theory. In the 1990s, process integration control technology has been highly developed and further utilized to compute the minimal fresh water consumption and wastewater generation, and to optimize the design of wastewater treatment systems. However, little work has been effectively conducted to couple the water pinch technology and the process integration control technology in industrial management due to its complexity in China. Therefore, continued follow-up research should be needed to fulfil the water conservation and wastewater reduction.

\section{Principle of Water Pinch Technology}

The basic idea of water pinch technology may be summed up in one sentence. That is, if the waste water discharged from a unit in a manufacturing process can meet the requirements of another unit for water quality, it should be provided for the later. It is noted that conventional water-saving measures usually consider just a single water unit or partial water network, while the water pinch technology takes the whole water network into account, distribute water quantity of the whole water network in rational, to enable the reuse of water in the system reaches the maximum, at the same time to minimize the amount of effluent discharge[2]. The mass transfer process between materials flow and water flow in water pinch technology can be illustrated, as shown Fig. 1. 


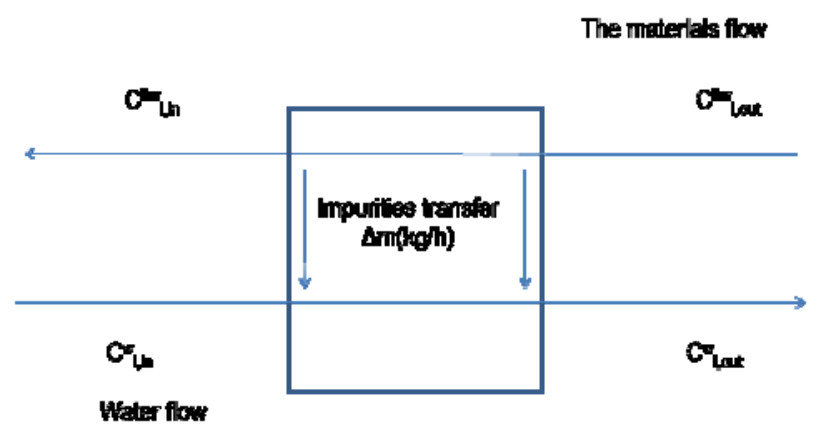

Figure1. Process flow model of rich impurities ${ }^{1}$

Where the $\mathrm{C}_{\mathrm{i}}^{\mathrm{lim}}$, in and $\mathrm{C}_{\mathrm{i}}^{\lim \text {, out }}$ respectively denote the import and export limitation concentrations of impurity in water uniti. Theactualimport impurity concentration of unit ican not exceedC ${ }_{i \text {, in }}$, and the actualworst export impurity concentration of unit $i$ does not exceed $C_{i \text {, out. The }}^{\lim }{ }_{i \text {, in }}$ is a hard constraints, while the bigger the $\mathrm{C}_{i}^{\lim }$, out the greater the optimization space of the unit $i$.

The $\mathrm{C}^{\mathrm{w}}{ }_{\mathrm{i}}$, in and $\mathrm{C}^{\mathrm{w}}{ }_{\mathrm{i}}$, out respectively represent the import and export impurity concentrations in water flow actually. While the materials flow conversely contacts with the water counter-current, the impurities in the former will enter into the later under stress of impurities transfer. Then, the wastewater with impurity concentration of $\mathrm{C}^{\mathrm{w}}{ }_{\mathrm{i}}$, out was present. It may be described as a mass transfer process from the materials flow containing rich impurities to the poor water flow ${ }^{[3]}$. This process can be illustrated by a C-M diagram, as shown in Fig. 2.

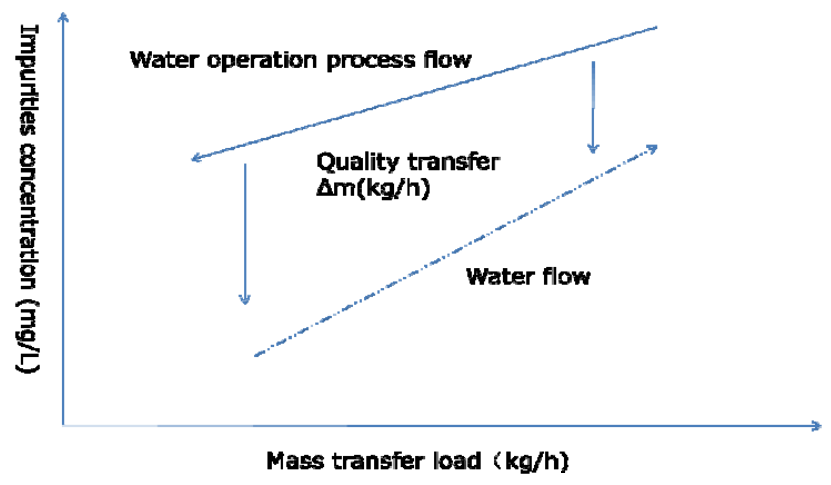

Figure2. Impurities load and transfer

From Fig.2, it can be seen that there is a limit water supply line below the material line, which contains the maximum impurity concentration in input and output water flow. Under the condition, the water consumption falls into the smallest. To achieve the global optimization for water networks, we must consider the water utilization in the context of the whole. Consequently, the compound curve would be recommended for the analyses on the water consumption of all water units. The concentration combination curves can be structured in Fig.3 (a). It is known that the water line below composite curve can all meet water supply demands. To minimize water supply, the slope of water supply line should be increased as much as possible. Then, the flow rate of fresh water becomes lower. But the slope of water supply line can not be enlarged without limit. It must meet the requirements that the water supply line should be below the limit of compound curves or overlap with them. To rotate the water supply line counter-clockwise until it intersects the composite curve, the first point that the two lines cut is called as pinch point, then the slope of water supply line reaches the maximum. At the same time, the minimum water supply of system required is also determined,as shown in Fig.3 (b).The minimal fresh water flow can be calculated by using Eq. 1. 


$$
\mathrm{f}_{\min }=\mathrm{M}_{\text {tot }} \backslash \mathrm{C}_{\text {pinch }} \times 10^{3}
$$

Where the fmin, Mtot, and Cpinch denotes the minimum fresh water flow $(\mathrm{t} / \mathrm{h})$, the total mass of impurity $(\mathrm{t} / \mathrm{h})$ and pinch point impurity concentration $(\mathrm{mg} / \mathrm{L})$, respectively.

(a)

(b)

Figure 3. Concentration combination curve graphics construction method

From above analysis, it can be found that the water unit above pinch point does not require fresh water recharge since the allowable value for inlet impurity concentration is greater than that of the pinch point. Meanwhile, we can reuse the drainage of other water units for utilization. On the contrary, if the water unit is below the pinch point, fresh water must be required since the limit of inlet impurity concentration requirement is less than that of the pinch point. The concentration combination curves can give the overall status of the water system, we can visually see the strengths and weaknesses of the current water system, bottlenecks that constrain the reuse of water, and the minimum fresh water consumption and minimum wastewater target value of the water system. According to the water pinch technology, it is not hard to see that the minimum amount of fresh water can be determined and the optimal water-using network can be designed based on the fresh water pinch.

\section{Measures and Steps}

The water-pinch technology can be performed by way of five steps in practical applications.

\section{Choice of Target System}

The principle of water-pinch technology is to optimize the water system from the viewpoint of global or total system. Specifically, the whole system may be an enterprise, a workshop, partial water units in a workshop and even water units among different workshops. For larger enterprise, we can divide the water network into a number of subsystems to research it according to the process route, different workshops and so on. As for multi-impurity system, the middle water tunnel technology is recommended for application[4-6].

\section{Screening of Major Water Units}

It is the key for reducing wastewater discharge and fresh water consumption to identify the major water unit. The water balance test and water quality analysis are first conducted for the target system when we select the major water unit. In normal conditions, the water unit can be selected as a major water unit, which the water consumption is greater than $5 \mathrm{t} / \mathrm{h}$, the water quality is worse than that of fresh water or the drainage water can be utilized as a water source of other water units. It should be pointed out that above process is just a semi-quantitative identification process. To further determine the main water units in the production process, the following steps should be performed: (1) to calculate the proportion of water input/output in each water unit accounts for the 
water input/output in the whole production system and arrange them in descending order; (2) to add them one by one in accordance with descending order until the sum excess $90 \%$. Then it can be thought that the sum of water quantity can represent the overall input/output level in the production process. So we can take these water units as the major water units[7].

\section{Determination of Pollutants Composition}

As mentioned above, the water-pinch technology is suitable for single-impurity water systems. And then, we can select the single impurity as a key one. As for multi-component system of impurities, we can select one of the major impurity components as the key impurity by means of test. Here the key impurity component usually means such component that most likely restricts wastewater reuse and has a major effect on the whole system. Thus, we can consider multi-component system as a single-impurity system to deal with.

\section{Determination of Load Limit for Impurity}

It is a troublesome problem for the water-pinch technology to determine the load limit for impurity component in the application. The solution methods mainly include analyses, qualitative comparison, assumptions and data review and so on[8,9].

\section{Calculation of Target Minimum Fresh Water}

The minimal fresh water flow can be calculated by graphic method, questionnaire method, or pinch technology optimization software[10], etc. There are two main ways to construct the water-using networks, namely the greatest mass transfer driving force and the minimum matching counting method. After the theoretical calculation and construct, the water networks usually need to be adjusted according to actual conditions, such as simplifying the water pipes and reducing the number of water sources for water supply units, etc.

\section{Case Study}

It is known that the water pinch technology has been adopted to cut down fresh water consumption in practical application. In this present study, we employ it for Coal chemical industry in Ningxia Province, China.

\section{Basic Data}

The data provided here are average values based on planning of The Ningdong Energy base throughout several coal mine in The Ning dong Energy base. We choose the major ten water units of coal mine as the water network system. The water-balance test method was used to conduct the water quantity testing, then the actual limit water consumption (flimi) of each unit was obtained. After planning and evaluation for the water quantity, the COD was considered as the key water quality parameters and was represented by potassium permanganate. The necessary restricted datum such as limiting input and output contaminant concentration, that were defined to Climi, in and Climi, out, were determined by COD with quantitative and semi-quantitative test method. The data were listed in Table 1. The limiting input concentration Climi, in must be lower than the limiting output concentration Climi, out in order to fulfil mass transfer, and it depends on the specific use of water. The $\triangle$ mi was defined to the mass load of COD contaminant of each unit. Here, $\triangle$ mi can be calculated by using Eq. 2.

$$
\triangle \mathrm{mi}=\text { flimi } \times(\text { Climi, out-Climi, in }) .
$$

Where Climi, in and Climi, out denote the limiting contaminant concentrations in the water supply and water stream leaving number i, respectively. The on-site survey data obtained after classification were listed in Tab1. From the data in Table1, we can see before optimization, each unit needs use fresh water for a total large amount of $960 \times 104 \mathrm{t} / \mathrm{a}$, and discharge of water (including 
evaporation and leakage) is $960 \times 104$ t/a correspondingly.

Table1. Limit process data

\begin{tabular}{cccccc}
\hline Number [i] & Coal Mine & $\mathrm{C}_{\mathrm{i}, \text { in }}^{\lim _{\mathrm{i}}}[\mathrm{mg} / \mathrm{L}]$ & $\mathrm{C}_{\mathrm{i}, \text { out }}^{\lim }[\mathrm{mg} / \mathrm{L}]$ & $\Delta \mathrm{m}_{\mathrm{i}}[\mathrm{t} / \mathrm{a}]$ & $\mathrm{f}_{\mathrm{i}}^{\lim }\left[10^{4} \mathrm{t} / \mathrm{a}\right]$ \\
\hline 1 & Ling xin & 10 & 43.3 & 17.982 & 54 \\
2 & Yang chang wan & 10 & 37.2 & 13.872 & 51 \\
3 & Zaoquan & 10 & 37.6 & 22.356 & 81 \\
4 & Qing shuiying & 10 & 41.0 & 48.36 & 156 \\
5 & Mei huajing & 10 & 102.1 & 171.306 & 186 \\
6 & Shi zaocun & 10 & 102.1 & 88.416 & 96 \\
7 & Hong liu & 10 & 102.1 & 116.046 & 126 \\
8 & Mai duo shan & 10 & 102.1 & 116.046 & 126 \\
9 & Ren jiazhang & 10 & 37.6 & 11.592 & 42 \\
10 & Ma lian tai & 10 & 45.9 & 15.078 & 42 \\
11 & Sum & & & & 960 \\
\hline
\end{tabular}

\section{Determination of the Minimum Fresh Water Target}

From the data in Table 1, the system water pinch point can be determined. The Fresh water pinch of the Ningdong Energy base is located at the minimum amount of $749.94 \times 10^{4} \mathrm{t} / \mathrm{a}$ for fresh water, as shown in Fig.4, and the $\mathrm{C}_{\text {pinch }}$ is the contaminant concentration of $84.72 \mathrm{mg} / \mathrm{L}$ correspondingly. It is clear that the water-saving effect was satisfied up to $21.88 \%$ compared to optimization before. Then, we target the minimum fresh water, design and adjust the entire water network to meet the requirements of $\mathrm{Tab} 1$.

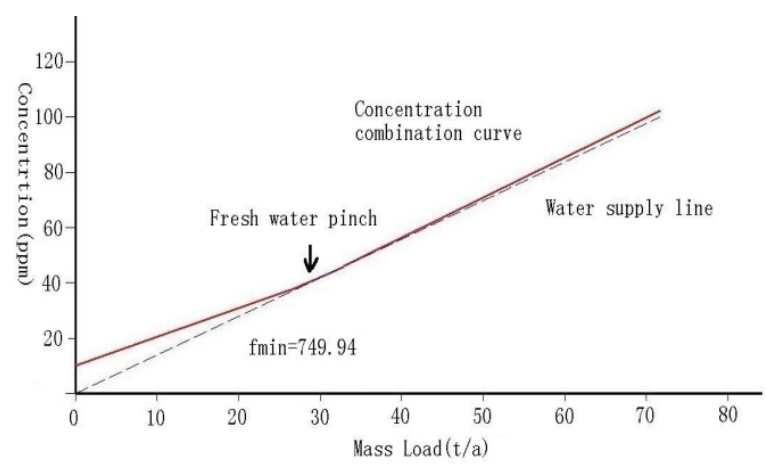

Figure 4. Fresh water pinch of the Ningdong Energy base

\section{Water Network Design and Adjustment}

In this study, the water-using network was designed by the greatest mass transfer driving force. This method can construct a water network to meet the target value of Tab1. Fig.5 illustrates the final design drawings obtained from water pinch point analysis. In order to maximize the water savings potential, the drainage COD concentration of all unit in this network maximized $\mathrm{C}_{\mathrm{i}}^{\lim \text {, out }}$ in Table 1.In addition to the unit 2,9,10completely supplied with fresh water, other units had use them iddle water to supplement fresh water in varying degrees. The middle water discharged by unit 2part supplied unit 1 and 3, then the middle water of the unit1,2,3,9,10 were collectively imported into a middle channel as used to supplement units 4,5,6,7,8 shortage of fresh water. According to this design, the results showed that under the premise of ensuring the water consumption of each unit $\left(\mathrm{f}_{\mathrm{i}}^{\mathrm{im}}\right)$, the influent COD concentration is less than or equal to allowed $\operatorname{limits}\left(\mathrm{C}_{\mathrm{i}}^{\mathrm{lim}}{ }_{\mathrm{in}}\right.$ in $\left.10 \mathrm{mg} / \mathrm{L}\right)$. Because of not involving the reclamation and reuse technologies, the final mixed wastewater COD concentration was exactly the theoretical value of $84.72 \mathrm{mg} / \mathrm{L}$ calculated by water pinch point analysis. 


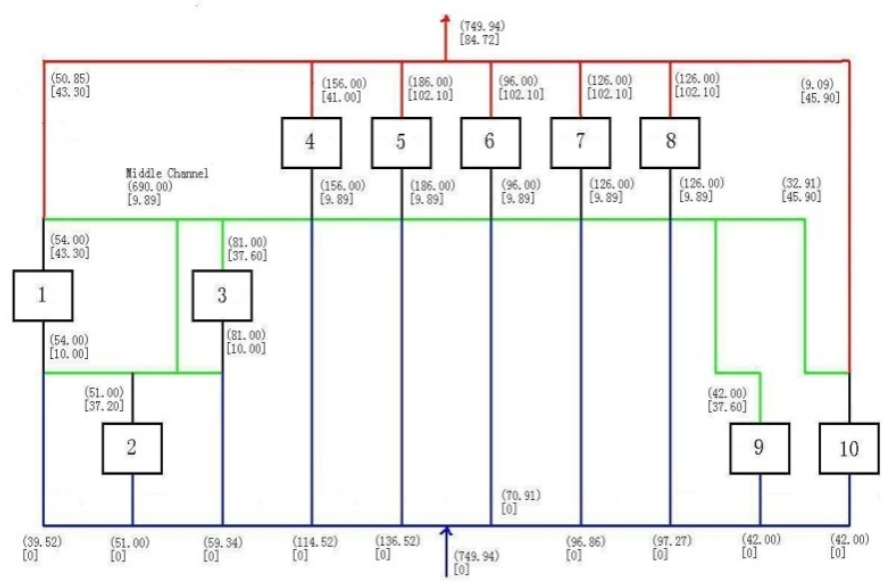

Figure 5. Water network optimization design

Numbers in parentheses are amount of fresh water in unit $10^{4} \mathrm{t} / \mathrm{a}$ Numbers in brackets are concentrations of contaminants COD in unit $\mathrm{mg} / \mathrm{L}$

\section{Conclusions}

The water network can be optimized by water pinch technology from a viewpoint of system. It can not only effectively decrease the consumption of fresh water, but also simplify the water network structure. In this present study, the water pinch technology was successfully employed for water-saving in a chemical industry, and $21.88 \%$ of the water resources were cut down. Furthermore, the system structure was also optimized. It should be pointed out that, however, the water pinch technology is based on the single impurity contaminant in water systems. As for the multi-impurity water systems, existing schemes is still far from perfect. Therefore, how to set up a mathematical model for multi-impurity component system and combine it with the water-pinch technology will be a hot spot.

\section{Acknowledgement}

This research was financially supported by the Chongqing decision consulting and management innovation program (cstc2016jccxAX0058).

\section{References}

[1] Wang Y P, Smith R. Waste water minimisation[J]. Chemical Engineering Science, 1994, 7:981-1006

[2] Yang Y H, Lou H H, Huang Y L. Synthesis of an optimal wastewater reuse network[J]. Water Management, 2000,20: 311-319.

[3] Feng X, Liu Y Z, Shen R J, et al. Water system integration optimization-system integration approach of water-saving and discharge reduction[M]. Beijing: Chemical Industry Press, 2008(in Chinese)

[4] Zheng P Y, Feng X, Qian F, et al. Water system integration of a chemical plant[J]. Energy Conversion and Management, 2006,47(15):2470-2478

[5] Feng X, Wang N S, Chen E B. Water system integration in a catalyst plant[J]. Chemical Engineering Research \& Design, 2006,84(8):645-651

[6] Cao D L, Wang B, Feng X. Application of internal water mains water system integration technology in the catalyst plant[J].Computers and Applied Chemistry, 2004, 21(3):437-439(in Chinese) 
[7] Wang Y, Yuan Z W, Bi J, et al. Metabolism analysis and optimization suggestions of the water system in the manufacturing processof glyphosate[J]. Research of Environmental Sciences, 2009, 22(1):1231-1236(in Chinese)

[8] Cao D L. Application of water pinch technology in petrochemical enterprises[J]. Petrochemical Technology in Jinshan, 2005, 24(1):22-26(in Chinese)

[9] Zuo Y S, Cang D Q, Li S Q, et al. Water treatment technology and wastewater minimization[J]. China Environmental ProtectionIndustry, 2007, 2:18-21(in Chinese)

[10] Liang W, Miao L, Zhang H L, et al. Application of the optimize software for water networks design to reduce industrial water[J].Mining \& Metallurgy, 2006, 5(9):390-393(in Chinese) 